\title{
Os significados da formação docente desenvolvida pelo Pacto Nacional pela Alfabetização na Idade Certa
}

\author{
Meanings of teaching education developed by the \\ National Pact for Literacy at the Right Age
}

\section{Los significados de la formación docente desarrollada por el Pacto Nacional para la Alfabetización en la Edad Apropiada}

\author{
Ana Maria Klein* \\ Monica Abrantes Galindo** \\ Solange Vera Nunes de Lima D’agua***
}

\begin{abstract}
Resumo: Este artigo investiga a formação continuada docente como política pública voltada ao enfrentamento do problema do analfabetismo nos anos iniciais do Ensino Fundamental, por meio das percepções de 1.515 professores alfabetizadores do noroeste paulista que participaram do programa federal Pacto Nacional pela Alfabetização na Idade Certa, PNAIC durante o ano de 2013. A formação docente é discutida com base nos autores Tardif, Imbernón e Nóvoa. Para a coleta de dados, foi utilizado um questionário com questões abertas e fechadas disponibilizadas em um servidor online para pesquisas. A metodologia adotada foi qualitativa e os dados revelam que os processos envolvidos na realização de uma formação, como trabalhos em grupo e metodologia, são tão valorizados quanto o acesso a novos conhecimentos.
\end{abstract}

Palavras-chave: Formação continuada em serviço. Percepções de professores alfabetizadores. Pacto Nacional pela Alfabetização na Idade Certa.

Abstract: This paper investigates the teaching continuing education as a public policy focused on confronting the illiteracy problem in the early years of elementary school, through the perceptions of 1.515 literacy teachers from the northwestern region of São Paulo that participated in the federal program Pacto Nacional pela Alfabetização na

\footnotetext{
* Professora da Universidade Estadual Paulista Júlio de Mesquita Filho (UNESP), campus de São José do Rio Preto. Consultora ONU/PNUD/UNESCO em Educação e Direitos Humanos. Coordenadora local do Pacto Nacional pela Alfabetização na Idade Certa (PNAIC). E-mail: <kleinana@uol.com.br>

** Professora da Universidade Estadual Paulista Júlio de Mesquita Filho (UNESP), campus de São José do Rio Preto. E-mail: <monica@ibilce.unesp.br>

*** Professora da Universidade Estadual Paulista Júlio de Mesquita Filho (UNESP), campus de São José do Rio Preto. Coordenadora do Plano Nacional de Formação dos Professores da Educação Básica (PARFOR/ CAPES) no IBILCE/UNESP. E-mail: <soldagua@ibilce.unesp.br>
} 
Idade Certa (National Pact for Literacy at the Right Age) during the year 2013. Teacher education is discussed based on the authors Tardif, Imbernón and Nóvoa. To collect data, a questionnaire with open and closed questions available on an online server for researches was used. The methodology was qualitative and the data shows that the processes involved in conducting training, such as group work and methodology, are as valued as access to new knowledge.

Keywords: Continuing education in service. Perceptions of literacy teachers. National Pact for Literacy at the Right Age.

Resumen: El trabajo investiga la formación continua como política pública encaminada a abordar el problema del analfabetismo en la fase inicial de la escuela primaria, a través de las percepciones de 1.515 alfabetizadores en el noroeste de São Paulo que participaron en el programa federal Pacto Nacional por la Alfabetización en la Edad Apropiada durante el año 2013. La formación de los docentes se discute sobre la base de los autores Tardif, Imbernón, Nóvoa. Se utilizó un cuestionario con preguntas abiertas y cerradas disponibles en un servidor en la web. La metodología fue cualitativa y los datos muestran que los procesos que intervienen en la realización de la formación como el trabajo en grupo y la metodología son tan apreciados como el acceso a los nuevos conocimientos

Palabras clave: Educación en servicio. Percepciones de los docentes de alfabetización. Pacto Nacional por la Alfabetización en la Edad Apropiada.

\section{Alfabetização nos anos iniciais do Ensino Fundamental: situando o problema}

Ler e escrever são conhecimentos e habilidades essenciais para a participação cidadã em todas as esferas sociais, além de serem imprescindíveis aos processos e às práticas educativas nas escolas. $\mathrm{O}$ analfabetismo atinge não apenas adultos ou jovens, mas também crianças que frequentam os anos iniciais do Ensino Fundamental e, por vezes, prosseguem seus estudos com conhecimentos rudimentares de leitura e de escrita. A comparação de dados dos censos dos anos de 2000 e 2010 mostram os índices de analfabetismo em cada região do Brasil. Ainda que haja uma diminuição nesses índices, o problema ainda é preocupante, atingindo cerca de 25\% das crianças até 8 anos no nordeste, 27\% no Norte, $9 \%$ no centro-oeste, $8 \%$ no sudeste e 5\% no sul (Gráfico 1 ).

Diante de tal cenário, a formação continuada de professores ganha espaço nas agendas políticas à medida que novos desafios são postos aos currículos e aos sistemas (GATTI, 2008, p. 58). A necessidade de acolher crianças em fase de 
alfabetização em suas dificuldades escolares impõe-se aos sistemas de ensino, e a formação docente é uma das respostas dadas a essa demanda.

No Brasil, a preocupação com a formação continuada cresceu consideravelmente a partir dos anos de 1990. A Lei de Diretrizes e Bases da Educação Nacional - Lei n. 9.394/96 (BRASIL, 1996) trata da questão em vários artigos, prevendo que os sistemas de ensino deverão promover a valorização dos profissionais da Educação e determinando que o aperfeiçoamento profissional continuado seja uma obrigação dos poderes públicos. Nesse contexto, insere-se o presente trabalho abordando a formação continuada docente no âmbito de um programa do governo federal brasileiro.

Gráfico 1 - Taxa de analfabetismo aos 8 anos de idade

Taxa de analfabetismo aos 08 anos (Censo IBGE)

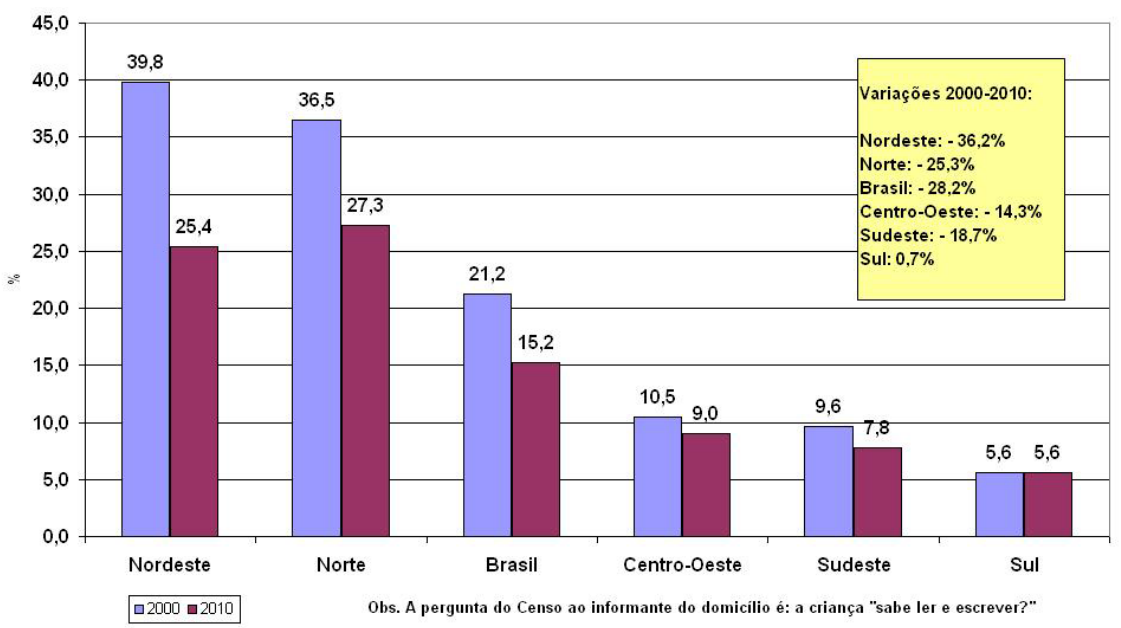

Fonte: Censo IBGE (2010 apud BRASIL, 2012).

\section{Formação de professores: saberes docentes e a relação teoria - prática}

Novos conceitos e novas pesquisas sobre a aprendizagem da linguagem oral e escrita vêm compondo o cenário educacional há algumas décadas. Teberosky (2001) entende que essas mudanças fazem emergir a necessidade da formação docente tanto em seu aspecto formal e teórico quanto na dimensão prática de sala de aula.

Para além dos novos conceitos relacionados à aprendizagem da língua oral e escrita, temos um contexto social marcado pela complexidade, pela diversidade 
dos alunos e pelas inovações tecnológicas, trazendo novos desafios à escola e à prática docente. Diante desse cenário, as discussões e as propostas de formação docente continuada ganham destaque.

A articulação entre a formação teórica e a valorização dos saberes docentes vem sendo enfatizada por diferentes autores (NÓVOA, 1991; TARDIF; LESSARD; LAHAYE, 1991; IMBERNÓN, 2010) que compreendem o caráter formador da experiência prática do professor. Nóvoa (1991) destaca a importância da formação continuada estar articulada à prática docente, alicerçando-se em uma reflexão na prática e sobre a prática por meio de dinâmicas de investigação-ação e de investigação-formação, valorizando os saberes de que os professores são portadores. Para o autor, a formação ganha significado e legitimidade se os programas estiverem estruturados em torno de problemas e projetos de ação, pautados na realidade escolar e não em conteúdos meramente teóricos.

Segundo Nóvoa (1991), o professor reflexivo e o professor pesquisador podem ser representados pelos profissionais que identificam suas práticas, discutem suas experiências, analisam situações e possibilidades com seus pares. Nesse sentido, o autor reconhece a possibilidade de a escola sustentar um trabalho coletivo, atentando para sua organização mediante a valorização do conhecimento profissional constituído pelo conhecimento disciplinar, conhecimento pedagógico e reflexão da experiência.

Em uma perspectiva semelhante de valorização dos saberes docentes e da articulação entre conhecimentos teóricos e práticos, há as ideias de Tardif, Lessard e Lahaye (1991) os quais destacam, dentre as atuais tendências, a valorização do saber docente, considerando o professor como um ator do ensino de saberes científicos. Os autores afirmam que, no ambiente no qual o professor desenvolve sua prática, há produção de conhecimento, admitindo que esse não seja proveniente apenas da teoria, mas construído também no cotidiano, nas experiências vivenciadas.

Imbernón (2010) também defende o equilíbrio entre a teoria e a prática, seja na formação inicial ou continuada, visando a introdução de novas perspectivas e novas metodologias. $\mathrm{O}$ autor indica que a efetivação de uma proposta formativa deve pautar-se em três pilares: a autonomia do professor, a discussão sobre os conteúdos curriculares e o reconhecimento da importância da comunidade. Já Kramer (1993) entende que a formação em serviço deve acontecer em torno de temas ou problemas detectados como relevantes ou diretamente sugeridos pelos professores.

A formação continuada em serviço de professores no Brasil vem sendo amplamente discutida como uma das vias principais de acesso à melhoria da qualidade do ensino (GATTI, 2003; NUNES, 2001; MONTEIRO, 2001 apud BRASIL, 2012) e ganha destaque nas agendas das políticas públicas. No entanto, muitas 
vezes os cursos de formação concentrados em um único espaço de tempo, por exemplo, sessenta horas de formação seguidas, não contribuem para a articulação entre a teoria e a prática docente. Ao término da formação, o professor volta à sala de aula e seu trabalho é executado de maneira solitária, sem a discussão sobre seu conhecimento prático e sem o apoio e a reflexão do curso proposto. Assim, temos momentos distintos: primeiro, forma-se e, depois, o professor volta à sala de aula. Os processos não são simultâneos, dificultando a problematização da prática no contexto formativo do curso. Por isso, uma formação que pretenda contribuir para a reflexão e a transformação da prática precisa buscar formatos que viabilizem a articulação entre teoria e prática e a valorização do saber docente em seu contexto de atuação.

Em uma perspectiva de articular teoria-prática com os saberes docentes, insere-se a proposta de formação docente do Pacto Nacional pela Alfabetização na Idade Certa, oferecido pelo Ministério da Educação em parceria com universidades e secretarias de educação de municípios e estados brasileiros.

\section{Alfabetização no Brasil e o Pacto Nacional pela Alfabetização na Idade Certa}

A alfabetização de crianças entre os seis e oito anos de idade é uma das metas do Plano Nacional de Educação (PNE) e do movimento Todos Pela Educação. O Brasil tem, hoje, quase 8 milhões de crianças matriculadas nos três primeiros anos do Ensino Fundamental em escolas públicas. Os dados coletados pelo Censo de 2010 revelam que $15,2 \%$ das crianças brasileiras com oito anos de idade ainda não sabem ler e nem escrever (ver gráfico 1).

Diante do cenário apresentado, foi lançado, em 2013, o Pacto Nacional pela Alfabetização na Idade Certa (PNAIC), programa federal que atua na formação de professores alfabetizadores e no fornecimento de materiais didáticos às escolas de todo o país. Trata-se de um compromisso assumido pelos governos federal, dos estados e dos municípios de assegurar que todas as crianças estejam alfabetizadas até os oito anos de idade, ou seja, ao final do $3^{\circ}$ ano do Ensino Fundamental. Segundo o Todos pela Educação (2013), participam do programa 5.413 municípios brasileiros (97\% do total de municípios do país), 16.842 orientadores de estudo, 283.469 professores alfabetizadores e 38 universidades. Todos os participantes recebem bolsas mensais pagas pelo Fundo Nacional de Desenvolvimento da Educação.

A estrutura da formação envolve a atuação de coordenadores, supervisores, formadores, orientadores de estudo e professores alfabetizadores. Os coordenadores e os supervisores são professores de universidades públicas que coordenam as atividades desenvolvidas nos polos regionais. Cada polo conta com formadores, 
profissionais graduados e pós-graduados com experiência na formação docente. Estes formam presencialmente orientadores de estudo, professores da rede pública com experiência em alfabetização e formação docente. Os orientadores de estudo, por sua vez, ao retornarem aos seus municípios após as formações nos polos regionais, formam professores alfabetizadores que atuam nos três primeiros anos do Ensino Fundamental. Trata-se de uma ação em rede.

O primeiro ano do PNAIC, dedicado à alfabetização em Língua Portuguesa, teve a duração de oito meses (abril a dezembro de 2013), integralizando 280 horas que intercalaram a formação presencial na universidade e atividades práticas desenvolvidas junto a professores alfabetizadores. Com isso, formação e atividades em sala de aula dialogaram permanentemente, em um ir e vir que possibilitou o exercício e a avaliação daquilo que foi estudado e planejado em cada encontro. Foram problematizadas situações concretas das salas de aula a partir de conceitos e teorias sobre alfabetização e letramento. Em seguida, planejadas ações interventivas (planejamentos da ação docente). O foco do PNAIC são ações voltadas à promoção dos direitos de aprendizagem das crianças; para os processos de avaliação e acompanhamento da aprendizagem; para o planejamento e avaliação das situações didáticas; para o conhecimento e uso dos materiais distribuídos pelo Ministério da Educação.

Os polos tiveram autonomia para o desenvolvimento das formações, desde que os princípios da formação fossem seguidos, a carga horária respeitada e os materiais produzidos pelo MEC fossem utilizados.

\section{As formações do PNAIC no noroeste paulista}

No polo em questão, os orientadores de estudo participaram de cinco encontros formativos com duração média de 32 horas e cerca de 45 dias de intervalo entre um e outro. Durante as semanas de formação, foram discutidos os cadernos que compõem o material, planejadas as formações que seriam realizadas com os professores alfabetizadores nos municípios; relatadas e discutidas as principais dúvidas e ações desenvolvidas pelos alfabetizadores em sala de aula. Os conteúdos dos cadernos foram desenvolvidos por meio de metodologia problematizadora, isto é, apresentava-se uma situação problema vivenciada em sala de aula a partir da qual os conteúdos dos cadernos eram discutidos visando-se compreender e buscar formas de enfrentar o problema apresentado. Para tanto, era imprescindível que os Orientadores de Estudo tivessem lido previamente os cadernos indicados para o encontro. Com isso, objetivou-se a articulação entre teoria (presente nos cadernos); prática (situação problema) e saberes docentes (formas utilizadas para enfrentar o problema).

Os encontros com os Orientadores de Estudo iniciavam-se com o relato das formações acontecidas no município. Esses relatos estruturavam-se sobre 
dois pontos: aspectos positivos da formação e dificuldades a serem enfrentadas. Após a semana de formação, os Orientadores de Estudo formavam os professores alfabetizadores nos seus municípios. Foram 10 encontros de 8 horas distribuídos ao longo dos meses. Os municípios tiveram autonomia para distribuir as 8 horas em um encontro de oito horas; dois encontros de quatro horas; ou quatro encontros de duas horas.

Os registros foram essenciais, tanto para fomentar a reflexão dos participantes quanto para a organização dos encontros seguintes. Após a formação dos Orientadores de Estudo nos polos, estes enviavam aos formadores um relatório avaliativo sobre os encontros, destacando o que consideraram positivo, emitindo críticas e levantando dúvidas ou pontos que gostariam de aprofundar. Além desse relatório, cada formador deveria enviar o planejamento da formação que realizaria com as professoras alfabetizadoras e, após a sua realização, um relatório sobre a formação no município.

Além dos relatórios e dos planejamentos, todos os Orientadores de Estudo e Professores Alfabetizadores produziram portfolios, cujo objetivo foi buscar o significado pessoal das formações e relacioná-los à prática em sala de aula. Esses registros resultaram em uma diversidade de produtos, retratando a compreensão e o envolvimento dos participantes. Foi também uma estratégia importante para favorecer a relação entre os conhecimentos advindos do curso e os saberes docentes.

Quadro 1 - Registros realizados pelos Orientadores de Estudo e Professores Alfabetizadores durante as formações

\begin{tabular}{|c|c|c|c|}
\hline Função & Registros Produzidos & Quando & Para quem \\
\hline $\begin{array}{c}\text { Orientadores de } \\
\text { Estudo }\end{array}$ & Relatório Avaliativo & $\begin{array}{c}\text { Ao final de cada semana } \\
\text { formativa nos Polos }\end{array}$ & Formadores \\
\hline $\begin{array}{c}\text { Orientadores de } \\
\text { Estudo }\end{array}$ & $\begin{array}{c}\text { Planejamento da } \\
\text { formação de professores } \\
\text { alfabetizadores }\end{array}$ & $\begin{array}{c}\text { Ao final de cada semana } \\
\text { formativa nos Polos }\end{array}$ & Formadores \\
\hline $\begin{array}{c}\text { Orientadores de } \\
\text { Estudo }\end{array}$ & $\begin{array}{c}\text { Relatório sobre a } \\
\text { formação de professores } \\
\text { alfabetizadores }\end{array}$ & $\begin{array}{c}\text { Ao final da formação nos } \\
\text { municípios }\end{array}$ & Formadores \\
\hline $\begin{array}{c}\text { Orientadores de } \\
\text { Estudo }\end{array}$ & Portfolio & $\begin{array}{c}\text { Registro de cada etapa } \\
\text { formativa }\end{array}$ & Formadores \\
\hline $\begin{array}{c}\text { Professores } \\
\text { alfabetizadores }\end{array}$ & Relatório Avaliativo & $\begin{array}{c}\text { Ao final de cada formação } \\
\text { de 8 horas nos municípios }\end{array}$ & $\begin{array}{c}\text { Orientadores de } \\
\text { Estudo }\end{array}$ \\
\hline $\begin{array}{c}\text { Professores } \\
\text { alfabetizadores }\end{array}$ & $\begin{array}{c}\text { Reflexão sobre as } \\
\text { atividades em sala de aula }\end{array}$ & $\begin{array}{c}\text { Ao final de cada formação } \\
\text { de 8 horas nos municípios }\end{array}$ & $\begin{array}{c}\text { Orientadores de } \\
\text { Estudo }\end{array}$ \\
\hline $\begin{array}{c}\text { Professores } \\
\text { alfabetizadores }\end{array}$ & Portfolio & Registro de cada etapa \\
formativa & $\begin{array}{c}\text { Orientadores de } \\
\text { Estudo }\end{array}$ \\
\hline
\end{tabular}

Fonte: Elaborado pelos autores com base nos registros realizados. 


\section{Metodologia}

A presente pesquisa restringe-se à região noroeste do Estado de São Paulo, cuja formação envolveu 98 municípios, 150 orientadores de estudo, cerca de 2.000 professores alfabetizadores, 5 formadores ligados à universidade (mestrandos ou doutorandos) e 2 supervisores locais (docentes da universidade).

O trabalho investiga as percepções de professores alfabetizadores do noroeste paulista sobre a formação em serviço oferecida pelo Pacto Nacional pela Alfabetização na Idade Certa, PNAIC, durante o ano de 2013. Dentre os objetivos do estudo, buscou-se a percepção dos professores sobre as mudanças que a formação propiciou na sua prática e os aspectos que consideraram mais significativos no transcorrer do curso.

A pesquisa tem caráter exploratório e a abordagem do problema é qualitativa. Segundo Bogdan e Biklen (1994), essa abordagem busca os significados que os sujeitos atribuem ao objeto estudado. Entende-se que, considerando as percepções dos formadores a partir de seu campo de atuação, se pode favorecer a proposição de formas de atuação convergentes com os desejos e as necessidades dos envolvidos.

Participantes: 88 municípios, 1.515 professores alfabetizadores que atuam nos três primeiros anos do Ensino Fundamental em escolas da rede pública de ensino. O número de respondentes em cada questão oscila, pois nem todos responderam a todas as questões. O instrumento é composto por questões abertas e fechadas e foi disponibilizado em um servidor de pesquisas online em dezembro de 2013.

\section{Perfil dos professores alfabetizadores participantes}

Em relação à faixa etária, cerca de $21 \%$ dos professores participantes têm entre 35 e 39 anos, 20\% entre 45 e 49 e 18\% entre 40 e 44 anos (Tabela 1).

Tabela 1 - Faixa etária dos professores alfabetizadores

\begin{tabular}{c|c|c}
\hline Faixa etária dos professores & $\mathbf{\%}$ & $\mathbf{F}$ \\
\hline 20 a 24 anos & $1,19 \%$ & 18 \\
\hline 25 a 29 anos & $9,64 \%$ & 146 \\
\hline 30 a 34 anos & $12,55 \%$ & 190 \\
\hline 35 a 39 anos & $21 \%$ & 318 \\
\hline 40 a 44 anos & $18,56 \%$ & 281 \\
\hline 45 a 49 anos & $20,28 \%$ & 307 \\
\hline 50 a 54 anos & $9,64 \%$ & 146 \\
\hline 55 a 59 anos & $5,48 \%$ & 83 \\
\hline 60 anos ou mais & $1,65 \%$ & 25 \\
\hline
\end{tabular}

Fonte: Elaborado pelos autores com base nos dados da pesquisa. 
Quanto à formação desses professores, a Tabela 2 demonstra que a grande maioria é licenciada em Pedagogia, 82\%, e mais da metade, 52\%, realizaram algum curso de especialização (lato sensu).

Tabela 2 - Formação acadêmica das professoras

\begin{tabular}{l|c|c}
\hline Formação dos professores & $\mathbf{\%}$ & $\mathbf{F}$ \\
\hline Pedagogia & $81,98 \%$ & 1.241 \\
\hline Letras & $9,77 \%$ & 148 \\
\hline Licenciatura em outras áreas & $15,64 \%$ & 237 \\
\hline Especialização & $51,88 \%$ & 786 \\
\hline Mestrado & $0,33 \%$ & 5 \\
\hline Doutorado & $0,00 \%$ & 0 \\
\hline Magistério $2^{\circ}$ grau & $36,96 \%$ & 560 \\
\hline
\end{tabular}

Fonte: Elaborado pelos autores com base nos dados da pesquisa.

\section{Autoavaliação e impacto da formação segundo a percepção dos professores}

Dentre as questões fechadas apresentadas aos professores participantes, destacamos duas: Como os professores se autoavaliam em relação à pontualidade; à assiduidade; à participação nas discussões e à leitura prévia dos textos indicados? O curso causou algum impacto na sua prática?

Tabela 3 - Autoavaliação - professoras

\begin{tabular}{l|c|c|c|c|c|c|c|c|c|c}
\hline \multirow{2}{*}{$\begin{array}{l}\text { Critérios de } \\
\text { autoavaliação }\end{array}$} & \multicolumn{2}{|c|}{ Ótimo } & \multicolumn{2}{c|}{ Bom } & \multicolumn{2}{c|}{ Indiferente } & \multicolumn{2}{c|}{ Ruim } & \multicolumn{2}{c}{ Péssimo } \\
\cline { 2 - 12 } & $\mathbf{F}$ & $\mathbf{\%}$ & $\mathbf{F}$ & $\mathbf{\%}$ & $\mathbf{F}$ & $\mathbf{\%}$ & $\mathbf{F}$ & $\mathbf{\%}$ & $\mathbf{F}$ \\
\hline Pontualidade & $90 \%$ & 1.268 & $10 \%$ & 138 & 0 & 0 & $0,2 \%$ & 3 & 0 & 0 \\
\hline Assiduidade & $87 \%$ & 1.230 & $13 \%$ & 177 & 0 & 0 & 0,01 & 1 & 0 & 0 \\
\hline $\begin{array}{l}\text { Participação nas } \\
\text { discussões }\end{array}$ & $83 \%$ & 1.164 & $17 \%$ & 238 & $0,2 \%$ & 3 & 0 & 0 & 0 & 0 \\
\hline $\begin{array}{l}\text { Leitura prévia } \\
\text { dos textos }\end{array}$ & $76 \%$ & 1.068 & $23 \%$ & 320 & $0,4 \%$ & 6 & $0,1 \%$ & 2 & $0,2 \%$ & 3 \\
\hline
\end{tabular}

Fonte: Elaborado pelos autores com base nos dados da pesquisa.

A grande maioria dos professores participantes avaliou sua participação/ atuação em todos os critérios apresentados como ótima. O critério que contou com a porcentagem mais baixa de ótimo, $76 \%$, foi leitura prévia dos textos indicados (Tabela 3). Isso indica que, na percepção dos participantes, houve um efetivo envolvimento e comprometimento com a formação. 
Tabela 4 - Impactos do curso

\begin{tabular}{c|c|c|c|c|c|c}
\hline \multirow{2}{*}{$\begin{array}{c}\text { Este curso causou algum } \\
\text { impacto na sua prática? }\end{array}$} & \multicolumn{2}{|c|}{ Muito } & \multicolumn{2}{c|}{ Razoavelmente } & \multicolumn{2}{c}{ Pouco } \\
\cline { 2 - 7 } & $\mathbf{\%}$ & $\mathbf{F}$ & $\mathbf{\%}$ & $\mathbf{F}$ & $\mathbf{\%}$ & $\mathbf{F}$ \\
\cline { 2 - 7 } & $70,40 \%$ & 975 & $23,47 \%$ & 325 & $6,14 \%$ & 85 \\
\hline
\end{tabular}

Fonte: Elaborado pelos autores com base nos dados da pesquisa.

Em relação aos impactos que a formação causou na prática docente, a maior parte dos professores participantes, $70 \%$, considera que houve muito impacto; $23 \%$ considera que foi razoável e, para $6 \%$, foi pouco (Tabela 4 ).

\section{Mudanças na prática pedagógica e aspectos significativos da formação}

Dentre as questões abertas apresentadas aos professores participantes, destacamos três: Questão A - "Quais foram as principais mudanças que você percebeu na sua prática após a formação?”; Questão B - "Para você, quais foram os aspectos mais significativos dessas formações?”, e Questão C - "Quais temáticas você gostaria de ver abordadas em uma próxima formação?”. As respostas foram categorizadas a partir das ideias expressas pelos professores participantes.

\section{Questão A: Quais foram as principais mudanças que você percebeu na sua prática após a formação?}

Com base nas respostas dos professores participantes, construímos 9 categorias para essa questão.

A-1 Organização do Trabalho pedagógico - refere-se ao esclarecimento de assuntos relacionados à organização do trabalho pedagógico como: registro, planejamento, definição clara de objetivos, projetos, sequência didática, rotina e avaliação.

Exemplo de resposta:

"Antes não tinha conhecimento e não sabia montar uma sequência didática e, hoje, já faço com clareza, além de me tornar menos rigorosa na hora de avaliar, respeitando os limites de cada aluno."

A-2 Mudanças metodológicas - refere-se às mudanças e/ou ao aprimoramento de metodologias em sala de aula como: priorizar o trabalho em grupo, participação ativa dos alunos, consideração da diversidade dos alunos, ênfase na aprendizagem, adequação das atividades ao nível dos alunos, trabalhar com a heterogeneidade e mapeamento da turma, interdisciplinaridade. 
Exemplo de resposta:

"Maior intencionalidade na minha ação pedagógica, uso da ludicidade e olhar individualizado para cada aluno dentro da heterogeneidade da turma."

A-3 Leitura/escrita - refere-se à busca em melhorar a competência de leitura e de escrita dos alunos, uso da leitura de deleite com regularidade, trabalho com gêneros textuais.

Exemplo de resposta:

"Meus alunos tornaram-se melhores leitores, consequentemente desenvolveram-se melhor na escrita, pois o trabalho com gêneros literários expandiu meus conbecimentos e dos meus alunos. Resultado que pode se perceber na Avaliação do SARESP.”

A-4 Grupo - refere-se a trocas e a experiências compartilhadas em grupo durante a formação.

Exemplo de resposta:

"Foi importante ouvir os depoimentos de colegas com as mesmas dificuldades na sala de aula e suas maneiras de resolvê-las."

A-5 Desenvolvimento dos alunos - refere-se ao favorecimento da aprendizagem dos alunos, ampliando o seu interesse.

Exemplo de resposta:

"Os alunos demonstravam uma ansiedade em aprender. Os resultados de cada atividade foram cada vez melhores como a leitura escrita e a própria expressão de cada um. Melhorou até mesmo o relacionamento entre colegas, pois tivemos a oportunidade de trabalhar em diferentes grupos."

A-6 Materiais e recursos - refere-se ao uso de jogos, cantinho da leitura, uso do computador, ludicidade na sala de aula, uso de livros de histórias e de materiais disponibilizados pelo PNAIC.

Exemplo de resposta:

"O uso dos materiais didáticos distribuidos pelo MEC. O cantinho da leitura, antes organizado com doações dos pais, agora ficou mais diversificado e interessante, pois, além dos livros, temos a caixa com os jogos."

A-7 Novos conhecimentos - refere-se à relação teoria e prática, a reflexões, a novos conhecimentos, ao novo olhar direcionado aos alunos.

Exemplo de resposta:

"Segurança no meu trabalho, que a teoria é fundamental para consolidar a prática." 


\section{A-8 Novos Olhares}

Exemplo de resposta:

"Um novo olhar na aplicação dos conteúdos e uma nova abordagem."

A-9 Sem mudanças - o curso não trouxe acréscimo ou mudanças para o cursista. Exemplo de resposta:

"De modo geral, não houve mudanças significativas."

A-10 Geral/ vaga - refere-se a respostas gerais ou vagas

Exemplo de resposta:

"Vejo a educação como algo que tem jeito!!!!"

Tabela 5 - Mudanças observadas na prática pedagógica segundo as professoras

\begin{tabular}{l|c|c}
\hline A. Quais foram as principais mudanças observadas na prática? \\
\hline \multirow{2}{*}{ Categorias } & $\mathrm{N}=1.349$ \\
\cline { 2 - 3 } & $\%$ & $\mathrm{~F}$ \\
\hline A-1 Organização do Trabalho pedagógico & $33 \%$ & 456 \\
\hline A-2 Mudanças metodológicas & $39 \%$ & 534 \\
\hline A-3 Leitura/escrita & $21 \%$ & 290 \\
\hline A-4 Grupo & $2 \%$ & 29 \\
\hline A-5 Desenvolvimento dos alunos & $13 \%$ & 178 \\
\hline A-6 Materiais e Recursos & $22 \%$ & 298 \\
\hline A-7 Novos conhecimentos & $15 \%$ & 204 \\
\hline A-8 Novos Olhares & $1 \%$ & 14 \\
\hline A-9 Sem mudanças & $3 \%$ & 41 \\
\hline A-10 Geral/vaga & $5 \%$ & 59 \\
\hline As
\end{tabular}

As respostas de alguns participantes mencionam mais de um instrumento, por isso uma mesma resposta pode ser classificada em mais de uma categoria. Consequentemente, a frequência e o total percentual ultrapassam $100 \%$.

Fonte: Elaborado pelos autores com base nos dados da pesquisa.

Pelos dados apresentados na Tabela 5, podemos perceber o quanto as mudanças metodológicas e as formas de organizar o trabalho pedagógico foram valorizadas pelo grupo em questão. Esses aspectos que juntos contam com $62 \%$ das respostas foram vivenciados pelos participantes durante as formações. Enfatizaram-se metodologias problematizadoras e registros que buscaram fomentar a reflexão sobre teoria-prática além de mobilizar saberes docentes. 
Os materiais e recursos disponibilizados pelo programa também foram mencionados por uma parcela significativa de professores, $22 \%$. Novamente, enfatiza-se a importância de elementos que favoreçam a transformação da prática. Já novos conhecimentos e leitura e escrita são aspectos mais associados aos conteúdos dos cadernos do Pacto e juntos reúnem 36\%.

\section{Questão B: Para você, quais foram os aspectos mais significativos dessas formações?}

Com base nas respostas dos professores participantes, construímos 9 categorias.

B-1 Organização do Trabalho Pedagógico - refere-se a aspectos que envolvem assuntos relacionados à organização do trabalho pedagógico como: registro, planejamento, definição clara de objetivos, projetos, sequência didática, rotina e avaliação.

Exemplo de resposta:

"Os aspectos mais significativos foram: o planejamento das atividades, a organização do trabalho, o tempo pedagógico e a construção da rotina, que promovem a aprendizagem efetiva dos alunos. Os jogos de alfabetização (10 jogos) são um ótimo recurso, muito importante no processo de aprendizagem. Com os jogos, criou-se um ambiente que favoreça a aprendizagem das crianças de maneira lúdica."

B-2 Mudanças metodológicas - refere-se a priorizar o trabalho em grupo, à participação dos alunos, à consideração das diversidades dos alunos, à ênfase na aprendizagem, à adequação das atividades ao nível dos alunos, a trabalhar com a heterogeneidade da sala.

Exemplo de resposta:

"A aprendizagem, os exemplos de projetos, atividades e sequências didáticas, principalmente por proporcionar situações, atividades concretas de como trabalhar em sala de aula, visando sempre a aprendizagem e evolução dos alunos."

B-3 Conteúdos e competências específicas - busca a melhoria na leitura e na escrita dos alunos, uso da leitura de deleite com regularidade, trabalho com gêneros textuais.

Exemplo de resposta:

"Aprofundamento ao trabalhar diferentes gêneros de textos apresentados aos alunos de maneira lúdica em livros paradidáticos, interligados a outros projetos trabalhados, tornando próximo da crianç e trabalhando a leitura em sala de aula." 
B-4 Trabalho em grupo - trocas de experiências compartilhadas em grupo. Formação docente.

Exemplo de resposta:

"O contato interpessoal, sendo representado na troca de experiências entre os educadores."

B-5 Aprendizagem - desenvolvimento dos alunos: favoreceu a aprendizagem dos alunos e seu interesse.

Exemplo de resposta:

"Percebi o quanto foi significativo para os alunos, diversificando as atividades de acordo com os grupos de alunos. O desenvolvimento deles foi muito melhor."

B-6 Materiais e recursos - favoreceu o uso de jogos, cantinho da leitura, uso do computador, ludicidade na sala de aula, uso de livros de historias, material do PNAIC.

Exemplo de resposta:

"Gostei muito da parte de jogos, dos livros do acervo, eles são muito ricos, e atingem os objetivos propostos."

B-7 Novos conhecimentos - relação teoria e prática, reflexões, novos conhecimentos, novo olhar direcionado aos alunos, diversidade de conteúdos e assuntos relacionados à inclusão.

Exemplo de resposta:

"Conhecer mais sobre a alfabetização e suas teorias, ler as experiências vividas em outras escolas através da leitura dos guias, compartilhar saberes e validar muitos deles na prática."

B-8 Direitos de aprendizagem - refere-se explicitamente aos direitos de aprendizagem estabelecidos pelo material.

Exemplo de resposta:

"Foi aprender e poder garantir os direitos de aprendizagem, pois até então eu não os conhecia."

\section{B-9 Tudo}

Exemplo de resposta:

"Praticamente todos os aspectos abordados foram significativos." 
Tabela 6 - Aspectos mais significativos segundo as professoras

B. Para você, quais foram os aspectos mais significativos dessas formações?

\begin{tabular}{l|c|c}
\hline \multirow{2}{*}{ Categorias } & \multicolumn{2}{c}{$\mathrm{N}=1292$} \\
\cline { 2 - 3 } & $\%$ & $\mathrm{~F}$ \\
\hline B-1 Organização do Trabalho Pedagógico & $8 \%$ & 115 \\
\hline B-2 Mudanças metodológicas & $16 \%$ & 213 \\
\hline B-3 Conteúdos e competências específicas & $7 \%$ & 105 \\
\hline B-4 Trabalho em grupo & $37 \%$ & 486 \\
\hline B-5 Aprendizagem & $2 \%$ & 38 \\
\hline B-6 Materiais e recursos & $15 \%$ & 204 \\
\hline B-7 Novos conhecimentos & $31 \%$ & 412 \\
\hline B-8 Direitos de aprendizagem & $4 \%$ & 64 \\
\hline B-9 Tudo & $6 \%$ & 84 \\
\hline As reposta dis
\end{tabular}

As respostas de alguns participantes mencionam mais de um instrumento, por isso uma mesma resposta pode ser classificada em mais de uma categoria. Consequentemente, a frequência e o total percentual ultrapassam 100\%.

Fonte: Elaborado pelos autores com base nos dados da pesquisa.

Os dados da Tabela 6 demonstram que a importância atribuída ao trabalho em grupo, 37\%, e aos novos conhecimentos 31\%, enfatizam dois aspectos complementares e fundamentais à formação continuada: o resgate do saber docente por meio dos trabalhos em grupo e o contato com novos conhecimentos e fundamentações teóricas.

\section{Questão C: Quais temáticas você gostaria que fossem tratadas em um curso de continuidade a este?}

Com base nas respostas dos professores participantes, construímos 14 categorias para essa questão.

C-1 Avaliação - refere-se à avaliação dos estudantes, sejam eles diagnósticas (sondagens) ou finais.

Exemplo de resposta:

"Como avaliar o ensino-aprendizagem?"

C-2 Escrita, produção textual, leitura - refere-se a conteúdos e a habilidades relacionadas ao domínio da leitura e escrita, incluindo aspectos do letramento.

Exemplo de resposta: 
"Prática da leitura e escrita dentro de um projeto, onde elas pudessem ser, ao final deste, leitoras e escritoras de suas próprias histórias no âmbito escolar e fora dele."

C-3 Indisciplina - refere-se a aspectos disciplinares ou a situações de indisciplina, à alusão ao comportamento dos estudantes, inclusive desinteresse e apatia.

Exemplo de resposta:

"Gostaria de uma orientação quanto à disciplina, pois vejo que as crianças não têm limites."

C-4 Inclusão - refere-se a aspectos das diversidades em sala de aula: ritmos de aprendizagem, dificuldades de aprendizagem, heterogeneidade, inclusão de portadores de necessidades especiais.

Exemplos de respostas:

"Gostaria que fossem abordados mais temas relevantes sobre a Inclusão, pois nos deparamos todos os dias com essa diversidade."

C-5 Interdisciplinaridade - refere-se explicitamente à interdisciplinaridade ou menciona a possibilidade do trabalho articulado de duas ou mais disciplinas.

Exemplo de resposta:

"Pensando na questão da interdisciplinaridade na formação do aluno, a continuidade deveria contemplar as outras áreas do conhecimento que congregam a educação básica."

C-6 Ludicidade - refere-se explicitamente à ludicidade e/ou ao uso de jogos, brincadeiras.

Exemplo de resposta:

"Oficinas, tralhando o lúdico vivenciando para ser aplicado em sala de aula."

C-7 Matemática - refere-se explicitamente à matemática e/ou às grandes áreas matemáticas ou ainda a conteúdos específicos.

Exemplo de resposta:

"Trabalhar a Matemática com ludicidade e leitura."

C-8 Metodologia/Planejamento - refere-se a aspectos relacionados à rotina, ao planejamento, ao registro de atividades.

Exemplo de resposta:

"Conteúdo Procedimental, aprender fazer, fazendo. - Encaminhamentos para atividades a serem realizadas em sala de aula. - Mais práticas atreladas a toda teoria que foi passada." 
C-9 Níveis de alfabetização - refere-se ao conhecimento sobre as diferentes etapas/ estágios/fases da aquisição da língua escrita (pré-silábico - ortográfico).

Exemplo de resposta:

"Curso que ajude a identificar os niveis de escrita."

C-10 Outras linguagens - refere-se à música, às artes, ao teatro.

Exemplo de resposta:

"Expandir a leitura e criatividade através de expressões corporais, músicas, danças..."

C-11 Participação da família - refere-se à necessidade de discutir a participação da família e dos alunos nos processos escolares.

Exemplo de resposta:

"Relação família e escola no processo de alfabetização. Tratando dos assuntos que envolvem a defasagem do acompanhamento da família na vida escolar dos alunos em processo de alfabetização e como o professor deve lidar com essa desestrutura que prejudica o desenvolvimento do aluno."

C-12 Valores - refere-se a aspectos éticos e valores, como respeito, tolerância, cooperação.

Exemplo de resposta:

"Como trabalhar valores em sala de aula."

C-13 Outras disciplinas - refere-se a outras disciplinas do currículo como Geografia, História etc.

Exemplo de resposta:

"No meu ponto de vista as temáticas deveriam ser baseadas nas demais disciplinas como Matemática, História, Geografia e Ciências para maiores esclarecimentos."

C-14 Sem sugestões - respostas que não apresentam sugestões.

Exemplo de resposta:

"Como eu poderia dizer algo de um contexto tão rico?" 
Tabela 7 - Temáticas que gostariam de ver abordadas segundo as professoras

\begin{tabular}{l|c|c}
\hline C - Quais temáticas você gostaria que fossem tratadas em um curso de \\
continuidade a este? & N $=1280$ \\
\hline Categorias & $\%$ & $\mathrm{~F}$ \\
\hline C-1 Avaliação & $2 \%$ & 33 \\
\hline C-2 Escrita, produção textual, leitura & $30 \%$ & 396 \\
\hline C-3 Indisciplina & $2 \%$ & 26 \\
\hline C-4 Inclusão & $22 \%$ & 288 \\
\hline C-5 Interdisciplinaridade & $2 \%$ & 38 \\
\hline C-6 Ludicidade & $6 \%$ & 85 \\
\hline C-7 Matemática & $20 \%$ & 257 \\
\hline C-8 Metodologia/Planejamento & $9 \%$ & 117 \\
\hline C-9 Níveis de alfabetização & $2 \%$ & 35 \\
\hline C-10 Outras linguagens & $3 \%$ & 49 \\
\hline C-11 Participação da família & $1 \%$ & 14 \\
\hline C-12 Valores & $2 \%$ & 27 \\
\hline C-13 Outras disciplinas & $3 \%$ & 43 \\
\hline C-14 Sem sugestões & $2 \%$ & 35 \\
\hline $\begin{array}{l}\text { As respostas de alguns participantes mencionam mais de um instrumento, por isso uma } \\
\text { mesma resposta pode ser classificada em mais de uma categoria. Consequentemente, a } \\
\text { frequência e o total percentual ultrapassam 100\%. }\end{array}$ & \\
\hline
\end{tabular}

Fonte: Elaboração própria.

Os dados da tabela 7 demonstram que os professores alfabetizadores sentem a necessidade de aprofundar ainda mais seus conhecimentos relacionados à escrita e produção textual, 30\%, além do conhecimento sobre Matemática, $20 \%$. Outro tema muito mencionado é a Inclusão, com 22\% das respostas.

\section{Considerações}

O perfil dos professores que responderam ao questionário mostra que $21 \%$ têm entre 35 e 39 anos, 20\% entre 45 e 49 anos e 19\% entre 40 e 44 anos; ou seja, 60\% têm entre 35 e 49 anos (Tabela 1). Em relação à formação acadêmica, 82\% são licenciadas em Pedagogia; 52\% tem algum curso de especialização; $16 \%$ são licenciadas em outros cursos e 10\% licenciadas em letras (Tabela 2). Um grupo maduro com boa formação inicial. 
O primeiro ano do PNAIC no polo em questão foi bem aceito pelos professores que se auto avaliaram positivamente e perceberam um impacto considerável da formação em sua prática profissional; $90 \%$ dos professores consideraram ótima sua pontualidade, $88 \%$ classificam sua assiduidade como ótima, 83\% auto avaliaram sua participação nas discussões como ótima e 76\% consideram sua leitura previa dos textos como ótima (Tabela 3). Tais dados podem indicar que, na percepção dos participantes, houve um efetivo comprometimento com a formação.

O curso teve muito impacto na prática docente para $70 \%$ dos professores; razoável para 24\% e pouco para 6\% (Tabela 4). Esse é outro dado que pode representar a importância de uma formação dessa natureza para transformar a prática docente. As principais mudanças observadas pelos professores na sua prática docente (Tabela 5) foram:

- Mudanças metodológicas - referem-se às mudanças e/ou ao aprimoramento de metodologias em sala de aula como: priorizar o trabalho em grupo, participação ativa dos alunos, consideração da diversidade dos alunos, ênfase na aprendizagem, adequação das atividades ao nível dos alunos, trabalhar com a heterogeneidade e mapeamento da turma, interdisciplinaridade - 39\%.

- Organização do Trabalho pedagógico - referem-se ao esclarecimento de assuntos relacionados à organização do trabalho pedagógico como: registro, planejamento, definição clara de objetivos, projetos, sequência didática, rotina e avaliação $-31 \%$.

- Materiais e recursos - referem-se ao uso de jogos, cantinho da leitura, uso do computador, ludicidade na sala de aula, uso de livros de histórias e de materiais disponibilizados pelo PNAIC - 22\%.

- Leitura e escrita - Referem-se à busca para melhorar a competência de leitura e a escrita dos alunos, uso da leitura de deleite com regularidade, trabalho com gêneros textuais - $21 \%$.

Foi mencionado, também, o trabalho em grupo (2\%), o desenvolvimento dos alunos $(13 \%)$, novos conhecimentos $(15 \%)$, novos olhares $(1 \%)$, ausência de mudanças $(3 \%)$.

Entende-se que as mudanças observadas na prática pedagógica (Tabela 5), especialmente a categoria "Organização do Trabalho Pedagógico", envolve registro, planejamento, projetos, avaliações, ou seja, elementos que foram efetivamente utilizados durante as formações (ver Quadro 1). As "mudanças metodológicas" também mencionadas pelos participantes (Tabela 5) foram experienciadas durante as formações que se desenvolveram a partir de metodologias problematizadoras visando a relação teoria-prática e a mobilização dos saberes docentes.

Os aspectos mais significativos da formação (Tabela 6) para as professoras foram: 
- Trabalho em grupo - trocas de experiências compartilhadas em grupo, 37\%.

- Novos conhecimentos - relação teoria e prática, reflexões, novos conhecimentos, novo olhar direcionado aos alunos, diversidade de conteúdos e assuntos relacionados à inclusão, 31\%.

Foram considerados como significativos, também, os seguintes aspectos: organização do trabalho pedagógico (8\%); mudanças metodológicas (16\%); conteúdos e competências específicas (7\%); aprendizagem (2\%); materiais e recursos (15\%); direitos de aprendizagem (4\%) e tudo (6\%).

Nessa questão, as categorias relacionadas aos conteúdos desenvolvidos durante a formação - organização do trabalho pedagógico, conteúdos especificos, novos conhecimentos e direitos de aprendizagem - contam também com cerca de um terço dos participantes (Tabela 6).

Os percentuais são significativos e demonstram a importância de uma formação eleger cuidadosamente não apenas os conteúdos, mas também os processos como possibilidades de compartilhamento de experiências entre os participantes, ou seja, a maneira como o curso se desenvolve e as possibilidades de interação que proporciona. Novos conceitos e conhecimentos são importantes, mas não são suficientes. Para esse grupo de participantes, a possibilidade de experimentar novas formas de "fazer" foi muito valorizada. A ênfase nos processos parece relacionar-se diretamente à concepção de formação na qual se priorizam aspectos relacionados a práxis pedagógica. As trocas entre grupos e a metodologia problematizadora articulam teoria e prática na medida em que problematizam o cotidiano e buscam conhecimentos conceituais para interpretar os fenômenos observados.

Por fim, investigaram-se as necessidades formativas dos professores que atuam nessa etapa da escolarização. As temáticas que gostariam que fossem abordadas em uma próxima formação (Tabela 7) são:

- Escrita, producão textual, leitura - referem-se a conteúdos e a habilidades relacionadas ao domínio da leitura e da escrita, incluindo aspectos do letramento $-30 \%$.

- Inclusão - refere-se a aspectos das diversidades em sala de aula: ritmos de aprendizagem, dificuldades de aprendizagem, heterogeneidade, inclusão de portadores de necessidades especiais, $22 \%$.

Os professores mencionam, ainda, matemática, 20\%; avaliação, $2 \%$; indisciplina, $2 \%$; interdisciplinaridade, $2 \%$; ludicidade, $6 \%$; metodologia e planejamento, 9\%; níveis de alfabetização, $2 \%$; outras linguagens (como música), $3 \%$; participação da família, $1 \%$; valores, $2 \%$; outras disciplinas, $3 \%$.

A partir desses dados, pode-se afirmar que o curso foi bem aceito pelas professoras, tanto em relação aos conteúdos abordados quanto em relação ao 
envolvimento e ao comprometimento das próprias participantes e de seus orientadores de estudo.

As questões abertas permitiram-nos localizar com mais precisão quais foram os pontos que mais agradaram aos participantes. Em relação às mudanças na sala de aula, ressalta-se a importância que os professores atribuíram às mudanças metodológicas, por meio das quais passaram a atribuir um papel mais ativo aos estudantes no processo ensino-aprendizagem e à importância da organização do trabalho pedagógico, além de práticas relacionadas mais diretamente à construção da escrita. Os aspectos mais significativos da formação destacam o trabalho em grupo e os novos conhecimentos.

A partir desses dados, podemos afirmar que tão importante quanto os conteúdos conceituais e os conhecimentos relacionados mais diretamente ao letramento e à alfabetização são a forma de trabalhar em sala de aula e a metodologia dos encontros que priorizou o trabalho em grupo dos professores.

\section{Contribuições e significado científico deste trabalho}

Os dados mostram que a formação docente continuada além de novos conteúdos deve estar atenta também ao processo de desenvolvimento do curso, priorizando a troca de experiências (que garante o espaço do saber docente) e a problematização da realidade visando a reflexão sobre o cotidiano a partir de novos conhecimentos. De maneira mais específica, este trabalho indica as necessidades formativas dos docentes que atuam nos anos iniciais do Ensino Fundamental.

\section{Referências}

BOGDAN, R.; BINLKEN, S. Investigação qualitativa em educação: uma introdução à teoria e aos métodos. Porto: Porto, 1994.

BRASIL. Lei n ${ }^{\circ}$ 9.394/96, de 20 de dezembro de 1996. Lei de Diretrizes e Bases da Educação Nacional. Estabelece as diretrizes e bases da educação nacional. Diário Oficial da União, Brasília, 23 dez. 1996. p. 27833.

BRASIL. Secretaria de Educação Básica. Diretoria de Apoio à Gestão Educacional. Pacto Nacional pela Alfabetização na Idade Certa: formação de professores no Pacto Nacional pela Alfabetização na Idade Certa. Brasília: MEC/SEB, 2012.

GATTI, B. A. Análise das políticas públicas para formação continuada no Brasil, na última década. Revista Brasileira de Educação, Rio de Janeiro, v. 13, n. 37, p. 57-70, jan./abr. 2008. DOI: $10.1590 /$ S1413-24782008000100006

IMBERNÓN, F. Formação continuada de professores. Porto Alegre: Artmed, 2010.

KRAMER, S. A formação do professor como leitor e construtor do saber. In: REUNIÃO ANUAL DA ANPED, 16., 1993, Caxambu. Anais... Caxambu, 1993. 
NÓVOA, A. Concepções e práticas da formação contínua de professores: In: NÓVOA, A. (Org.). Formação contínua de professores: realidade e perspectivas. Portugal: Universidade de Aveiro, 1991. p. 30-42.

TARDIF, M.; LESSARD, C.; LAHAYE, L. Os professores face ao saber: esboço de uma problemática do saber docente. Teoria \& Educação, Porto Alegre, n. 4, p. 215-233, 1991.

TEBEROSKY, A. A alfabetização e a formação de professores nas diferentes etapas educacionais. In: CONGRESSO BRASILEIRO DE QUALIDADE NA EDUCAÇÃO, 1., 2001, Brasília. Anais... Brasília: Centro de Convenções Ulysses Guimarães, 2001. Disponível em: <http:// portal.mec.gov.br/seb/arquivos/pdf/volld.pdf>. Acesso em: 27 jul. 2015.

TODOS PELA EDUCAÇÃO. PNAIC está presente em 97\% dos municípios do país. 2013. Disponível em: < http://www.todospelaeducacao.org.br/noticias-tpe/27323/pnaic-estapresente-em-97-dos-municipios-do-pais/?pag=119>. Acesso em: 24 jul. 2015.

Recebido em 18/11/2014

Aceito em 29/06/2015 